\title{
Visibility of the Sri Lanka Journal of Child Health in the global electronic information circuit
}

Sri Lanka Journal of Child Health, 2009; 38: 48

It is now almost a decade since The Sri Lanka Journal of Child Health got itself into the electronic information super-highway of the internet. Until recently, the Journal was featured only as a standalone Uniform Resource Locator (URL) in the domain site of The Sri Lanka College of Paediatricians at $<$ www. srilankacollegeofpaediatricians.com $>$. It was just one of the countless numbers of medical journals on the internet. One had to specifically look for and go to the URL to look at the Journal. The "hits" were probably only few and far between in spite of regular publication of the Journal quarterly. The exact statistics and details of the number of hits and viewing by readers were not available till very recently.

Two developments in the last couple of years have helped to increase the visibility of the Journal over the internet. One is its listing in the search engine Google. The other is the Journal being included in the URL, Sri Lanka Journals On Line (SLJOL), at $<\underline{\text { www.sljol.info }}>$. Getting into Google has markedly increased the visibility of the Journal as the search engine is perhaps the most popular one amongst all internet browsers. Many people, including medical professionals are known to use Google extensively. The SLJOL enterprise is a commendable and much valued venture of the Internet Network for the Availability of Scientific Publications (INASP) and is modelled on their own original initiative of the African Journals On Line (AJOL). The Sri Lankan Journals On Line URL is specifically dedicated to Sri Lankan Scientific Journals. Interestingly enough, The Sri Lanka Journal of Child Health (SLJCH) was the first one to be enrolled into the URL. All new issues of this Journal are promptly incorporated into the site together with the hard-copy release of the publication. It has come out regularly and on time, quarterly. The Sri Lanka College of Paediatricians has deemed it fit to ensure full text availability of all articles, completely free of charge, over the internet.

In any enterprise, it is always beneficial to review progress and to do a little bit of soul-searching from time to time. One of the ultimate accolades for a journal is its readership in numerical terms. Up to now, we have had precious little information on the global visibility of our Journal. Information on the "hits", if any, was based merely on anecdotal evidence. This position has now changed with the advent of the SLJOL. The URL has the facilities to monitor the hits and views of each of its component journals. In the most recent edition of the SLJOL Newsletter, available at $\left\langle\underline{w w w . s l j o l . i n f_{O}}>\right.$, some concrete information is available as to the many

instances where articles from the journals were accessed by interested individuals.

During the period of three months from September 2008, there were 1364 visits from 82 countries to the main URL. It has exponentially increased over the three month period. Most of the visitors were from the United States of America (USA), Canada, United Kingdom (UK) and India. Within the country of Sri Lanka, there were 341 visits from 4 cities. The most number of foreign visits were from the UK where there were 259 visits from 51 different cities.

Our Journal allows free access of all articles on a full text basis. As chronicled in the SLJOL Newsletter, articles from our Journal have the highest number of general views and views per specific article. In point of fact, nine out of the top ten articles viewed in the parent URL of SLJOL are from The Sri Lanka Journal of Child Health. In the period under review, SLJCH had the highest number of views at 4890 and the highest number of views per article at 450 . We have even done better than our country's illustrious grand old medical journal, The Ceylon Medical Journal (CMJ). It is indeed a proud moment for The Sri Lanka Journal of Child Health and is probably an acknowledgement of the efforts taken to maintain a pre-set standard and thereby the quality of the articles published.

The Sri Lanka College of Paediatricians has reappointed its current Joint Editors of The Sri Lanka Journal of Child Health for a further period of three years. The College has also provided them with a dedicated panel of intellectuals in the Local Editorial Board as well as a vastly experienced conglomerate of medical professionals with a proven track record in the International Advisory Panel. These manoeuvres were designed just to make something good, that much better. It is hoped that the Journal would go from strength to strength from here onwards. The readership has the assurance from the Joint Editors that there will not be any deviation from this stated goal of achieving the zenith of excellence.

\section{B.J.C.Perera} Joint Editor 